\title{
Criatividade, inovação e controle nas organizações*
}

\author{
Maria Cristina Sanches Amorim \\ Ronaldo Frederico ${ }^{\prime}$ \\ Pontifícia Universidade Católica de São Paulo
}

\section{Resumo}

A criatividade, característica da força de trabalho, e a inovação, resultado da criatividade na forma de mercadoria, são imprescindíveis para a acumulação capitalista. A criatividade é imaterial, não mensurável em termos de trocas relativas, enquanto a inovação assume a forma de processos ou produtos. As organizações, diante da necessidade de apropriação da criatividade, desenvolvem controles intensos, nas intermináveis relações de poder e contra-poder. Este artigo discute criatividade e inovação nas organizações como foco privilegiado do controle sobre a força de trabalho. Pretendendo ser um ensaio teórico, a metodologia consistiu na revisão da literatura marxista e na crítica de parte da bibliografia voltada para o management, segundo a qual autonomia e liberdade são bases para a criatividade. As considerações finais apontam que, enquanto aumenta a taxa de inovação, são ampliados a subsunção do capital sobre o trabalho, a alienação dos ditos "executivos" e o acirramento da ética individualista.

Palavras-chave: Criatividade; inovação; management; Marx; crítica.

\begin{abstract}
Creativity, characteristic of the workforce, and innovation, result of the creativity in the form of goods, are essential for the capitalist accumulation. Creativity is immaterial, not measurable in terms of relative trades, while innovation assumes the form of processes and products. Organizations, in face of the need to appropriate the creativity, develop intensive controls in the endless relations of power and counter-power. This work aims to examine the creativity and innovation in the organizations as the focus of control over the workforce.

\footnotetext{
* Creativity, innovation and organizational control Campo, SP, 09715-140 (ronaldo.frederico@ig.com.br).
}

1 Endereço para correspondências: Rua Brasílio Machado, 280, ap. 131, Centro, São Bernardo do
\end{abstract}




\title{
HUMANAS
}

Wishing to be a theoretical academic essay, the methodology used was the revision of the Marxist literature and the criticism about part of the management literature, according to which, autonomy and freedom are the basis for creativity. Our final considerations point that while increasing the rate of innovation, are expanded the subsuntion of labour to the capital, the alienation of such "executives" and the incitement of individualistic ethics.

Keywords: Creativity; innovation; management; Marx; criticism.

\section{Introdução}

\begin{abstract}
A s relações entre criatividade, inovação e desenvolvimento econômico são crescentemente discutidas, em virtude da importância do conhecimento no processo produtivo capitalista contemporâneo. No mundo do management, organizações e profissionais são estimulados a criar ambientes propícios à criatividade ou à inovação, sem, no entanto, considerar que, em nome de maiores taxas de inovação, intensificam-se os instrumentos de controle sobre o processo, resultado e a força de trabalho. Interessa discutir criatividade e inovação nas organizações como foco privilegiado do controle sobre a força de trabalho, que tem por finalidade última ampliar o retorno sobre o capital investido.

De acordo com Schumpeter (1982), o desenvolvimento econômico depende, em última instância, da inovação tecnológica, da introdução e difusão de novas invenções geradoras de mudanças estruturais denominadas "destruição criativa", em substituição a antigos hábitos de consumo por novos. $\mathrm{O}$ empresário inovador é o herói da saga do desenvolvimento econômico, por meio do qual a sociedade tem acesso a padrões de vida mais elevados.

De acordo com Marx (1983a), a inovação é igualmente fundamental para o chamado desenvolvimento econômico, porém, não como resultante do pendor inovador de um grupo de empresários, mas como forma de aumentar a extração de mais-valia relativa do trabalhador, esta, por sua vez, origem do lucro. Dada a competição crescente entre capitais, ampliar a taxa de lucro é condição de sobrevivência das organizações.

Definida como característica da força de trabalho, a criatividade é imaterial, subjetiva e intangível, portanto, como controlá-la, como submetê-la à necessidade da acumulação? Ao capital não interessa qualquer criatividade,
\end{abstract}


apenas aquela considerada, no contexto socioeconômico, capaz de resolver problemas relevantes ou criar o novo (GARDNER, 2003). Como solucionar tal impasse? Na incapacidade de subordinar a criatividade, a organização volta-se para seu resultado, a inovação, só considerada como tal quando assume forma de mercadoria, ainda que a mensuração de seu valor seja complexa e potencialmente desestabilizadora do sistema geral de equivalência das trocas comerciais (GORZ, 2005).

Se são infinitas as possibilidades de exercício de poder (FOUCAULT, 2005), nas organizações, as disciplinas são transformadas em modelos de gestão utilizados de acordo com o contexto socioeconômico geral e, em certa medida, também pelos modismos ditados por best-sellers da área. Na primeira década do século XXI, no Brasil, por exemplo, houve predileção pelo $B a$ lance Scorecard (BSC) - criado por Kaplan e Norton (1997). BSC e a conhecidíssima Total Quality Management (TQM) expressam parte das tentativas das organizações de controlar a inovação. Quais são as conseqüências do controle da inovação para os indivíduos (ditos executivos) e para a sociedade?

\section{Criatividade e inovação nas organizações}

De acordo com a etimologia das palavras, o termo criatividade deriva do latim creare, que significa criar, inventar, fazer algo novo. Inovação vem do latim innovare, que significa tornar novo, mudar ou alterar as coisas, introduzindo nelas novidades, renovar (PAROLIN, 2001).

Nos limites do presente artigo, diferenciam-se criatividade e inovação: a primeira é geração de idéias (por meio de conceitos, teorias e processos que se apresentam ao longo da história) e a segunda é prática, fazer, implementar as idéias geradas pela criatividade. $O$ estudo de ambas recebe contribuições de diversas áreas do saber, como a filosofia, psicologia, sociologia e administração.

Ao dividir cronologicamente as teorias sobre criatividade, tal qual proposto por Wechsler (1998), tem-se, na tradição não-empírica, criatividade como inspiração divina, como forma de intuição (na linha cartesiana) e como loucura. $\mathrm{Na}$ abordagem biológica, marcada pela teoria evolucionista de $\mathrm{Da}$ rwin, é manifestação da força criadora inerente à vida, é força vital, sempre gerando novas espécies, com inesgotável variedade de formas peculiares, sem precedentes e sem repetições. Seu componente principal é a hereditariedade, não sendo possível educar uma pessoa para a criatividade. 


\section{HUMANAS}

Na abordagem psicológica (SENS, 1998), o behaviorismo centra-se na predição e no controle do comportamento, sendo o processo criativo decorrente de combinações mentais armazenadas por meio das experiências vivenciadas pelas pessoas, ou seja, criatividade é o resultado de uma associação com algo concreto de sua vida. $\mathrm{Na}$ Gestalt (ver WERTHEIMER, 1959) a criatividade é a procura de solução para uma gestalt, situação para a qual é necessário encontrar soluções. Na psicanálise (ver KNELLER, 1978), a criatividade resulta do conflito no inconsciente (id) provocador de um comportamento de criação ou de neurose. Na psicologia humanista (ver ALENCAR e FLEITH, 2003), três representantes - Rogers, Maslow e Rollo May - apontam que a tendência humana em direção à auto-realização é a força motora da criatividade, sendo indispensável um ambiente que propicie a liberdade de escolha, o livre-arbítrio para cada indivíduo, levando-se em conta as motivações individuais intrínsecas e extrínsecas do meio no qual ele vive. $\mathrm{Na}$ abordagem cognitiva, a criatividade se associa a inteligência e à solução de problemas - uma das abordagens mais famosas e utilizadas no campo cognitivo foi criada por Howard Gardner (1994), que questionou a centralidade da inteligência nas competências lógico-matemáticas e linguísticas, o que resultou na teoria das inteligências múltiplas. As abordagens de Gardner (1994) e da autodenominada psicologia humanista são muito utilizadas nas organizações. A primeira, por ter direcionado seus estudos para a aplicação das múltiplas inteligências dentro dos parâmetros capitalistas, ou seja, a capacidade para criar produtos e solucionar problemas, associando sua efetividade aos resultados financeiros: redução de custos e despesas e aumento de receita. A segunda tanto alimenta o senso comum de que criatividade exige liberdade como contribui para ocultar as relações entre controle e inovação.

A psicologia humanista não explicaria, por exemplo, a produção de Gramsci (1987) e Graciliano Ramos (1980), cujas obras máximas foram produzidas no período do cárcere. Foucault (2005), ao contrário, mostra que ambientes altamente inóspitos (como cárceres e manicômios) não eliminam a criatividade de suas vítimas. Interessa seguir essa última abordagem, sustentando que não há contradições entre aumento de controle e da taxa de inovação nas organizações capitalistas.

As abordagens sobre inovação são baseadas, principalmente, no aspecto concreto de seu resultado, como um novo produto ou serviço, bem como o meio utilizado para produzi-lo (tecnologia, por exemplo). 
Criatividade, inovação e controle nas organizações Maria Cristina Sanches Amorim e Ronaldo Frederico

A teoria da inovação foi formulada pelo economista austríaco Joseph Alois Schumpeter, ao observar que as longas ondas dos ciclos do desenvolvimento no capitalismo resultam da combinação de inovações, que criam um setor líder na economia ou um novo paradigma, passando a impulsionar o crescimento rápido dessa economia (SCHUMPETER, 1982).

A literatura sobre criatividade e inovação aplicada às organizações tem foco em três dimensões: 1) as características das pessoas altamente criativas e inovadoras; 2) o ambiente favorável à expressão da criatividade e inovação; 3) as habilidades cognitivas do pensamento criativo e inovador. Todas têm abordagem sociointeracionista da criatividade, a qual inclui as seguintes condições para que o processo criativo ocorra: a pessoa criativa, as relações interpessoais, o ambiente organizacional e as relações do sujeito criativo com a organização (PAROLIN, 2001). Não raramente, os termos criatividade e inovação são utilizados como sinônimos.

A criatividade é considerada inerente ao indivíduo, e suas habilidades criativas, passíveis de estímulo e desenvolvimento mediante treino, cabendo às organizações desenvolver ambiente favorável à criatividade, inclusive com políticas de incentivo para ir além da valorização do profissional (ALENCAR, 1993).

A bibliografia sobre o tema criatividade e inovação aplicada às organizações também abrange desde a abordagem atitudinal até relatos de experiências sobre possíveis erros e acertos em empresas, incluindo modelos de processos criativos.

Assim, dividiu-se a literatura sobre criatividade e inovação nas empresas em três tipos básicos:

Baseada em casos reais: A partir de análise empírica de fatos ocorridos em diversos casos, os autores obtêm modelos sustentados por meio dos resultados obtidos nas empresas, conceituando-os como certos e errados. Verifica-se o contexto no qual os resultados foram obtidos e se extraem dele as razões que levaram ao sucesso ou ao insucesso. Nesse grupo, citam-se Taffinder (1998), Robinson e Stern (1997), Christensen (2003), Chesbrough (2003), Kanter, Kao e Wiersema (1998), Kelley e Littman (2007).

Baseada em teorias médicas neurológicas e da psicologia: Uma vez que criatividade e inovação são fenômenos inerentes ao ser humano, 
aplicam-se as diversas teorias da neurologia e da psicologia para bem entender e conceituar o tema. Alguns autores abordam primeiro a psicologia aplicada à organização, para depois inserir a criatividade e inovação no contexto. Como parte desse grupo, podem-se citar: Alencar (1993); Gardner (2003 e 1996); Land e Jarman (1992) e May (1982). Baseada em processos e procedimentos: Conceitua-se criatividade $\mathrm{e}$ inovação como algo tácito, possível de se aprender e ensinar, sendo gerada uma série de processos, os quais consistem de diversos passos para se obter os resultados esperados. Criam-se espécies de fórmulas para sua aplicação prática. Como exemplos, há: Kelley (2002), Ayan (2001), Clegg e Birch (2000), Predebon (2003) e Drucker (2002).

No nível das organizações, quaisquer que sejam as "origens teóricas" da criatividade e da inovação, importa fundamentalmente identificar uma forma de incentivar a inovação, ainda que a ferramenta (ou forma) seja mistura sem critérios e conflitante nos instrumentos.

À procura da ferramenta de gestão para ampliar a inovação, é necessário que os objetivos e métricas estejam definidos. Como identificar se uma idéia ou atitude é mais criativa do que outra? Como saber se um indivíduo é mais inovador do que seu colega? As respostas dadas pelas organizações a esses questionamentos partem da definição de objetivos e métricas quantitativas, preferencialmente, financeiras. Peter Drucker, em Inovação e espirito empreendedor (2002), apresenta uma visão sobre processos existentes em diversas empresas que, por meio da experiência e observação de casos reais, podem ser desenvolvidos e constantemente melhorados para se obter 0 máximo de o que chama de "fontes de oportunidades inovadoras".

A inovação é o instrumento específico dos empreendedores, o meio pelo qual eles exploram a mudança como uma oportunidade para um negócio diferente ou um serviço diferente. Ela pode ser apresentada como disciplina, ser apreendida e ser praticada (DRUCKER, 2002, p.25).

Essas fontes ou princípios da inovação são enumerados pelo autor como, dentre outros, o inesperado, as incongruências, mudanças demográficas, 
Criatividade, inovação e controle nas organizações Maria Cristina Sanches Amorim e Ronaldo Frederico

percepção, conhecimento novo, idéia brilhante. As conclusões são obtidas por Drucker (2002) após análise superficial dos objetos que compõem suas observações. Os inúmeros casos reais citados em passagens do livro demonstram foco no resultado obtido, e não nas conseqüências mais amplas, e, fundamentalmente, não indicam um método. Por exemplo, o número de patentes é uma informação importante para Drucker, na análise das oportunidades de inovação, independentemente de quais benefícios (ou malefícios) essas patentes possam trazer para a sociedade.

Mais uma demonstração da conexão entre criatividade, inovação e resultados financeiros da organização é o termo "inovatividade". Criado nos anos 90 , ele alia a competência em inovação à capacidade produtiva da empresa, verificando em que medida uma empresa é mais inovadora em comparação com outras. Essa medição é feita por meio de indicadores (índice de novos produtos lançados por uma empresa em determinado período, participação de mercado desses produtos, além da redução de custos, principalmente em processos) (BONELLI et al., 1994).

Em síntese, o exame da literatura do management mostra o significado da criatividade e da inovação nas organizações: processo pelo qual o trabalhador gera produto ou serviço de reconhecível valor econômico para a empresa. A inovação é produto da criatividade, sendo a última a matéria-prima necessária para existência da primeira (GARDNER, 1996). Dito de outra forma, inovação é a criatividade transformada em mercadoria, portanto, as empresas estão interessadas na criatividade, na inovação ou em ambas? Qual é o principal objetivo da criatividade e inovação nas organizações?

\section{Inovação, ferramenta para acumulação de capital}

Não é recente a compreensão do uso da inovação como ferramenta para aumento da acumulação de capital e lucratividade das empresas. Schumpeter (1982) cunhou a expressão "destruição criadora", utilizando-a juntamente com o conceito de ciclo econômico para explicar o capitalismo e o desenvolvimento.

Os ciclos econômicos, ou seja, os períodos de crescimento, prosperidade e recessão existentes no capitalismo, não são resultados do aumento da população, renda ou riqueza. Conforme as inovações são absorvidas pelo mercado, generalizando o consumo, tem início um processo recessivo na economia, 
com a diminuição da taxa de crescimento e redução dos investimentos. Isso permanecerá até que uma nova combinação de um empreendedor inovador ocorra, dando início a um novo ciclo (SCHUMPETER, 1982). Tem-se assim a relação entre inovação, empreendedorismo e desenvolvimento econômico, na perspectiva schumpeteriana.

Influenciado pela obra de Marx, Schumpeter avalia a possibilidade do declínio das oportunidades de investimento que ocasionariam a redução da taxa de lucro do capitalismo. A teoria schumpeteriana é baseada no lucro e nos reinvestimentos de parte dos lucros (ou mediante o acesso ao crédito) e tem como cerne a inovação, elemento motriz que rompe com uma situação de estagnação econômica.

A abordagem marxista, segundo a qual a inovação é ferramenta para acumulação de capital, estrutura-se nos conceitos de trabalho concreto e abstrato, de valor e de mais-valia. É desnecessário, nos limites desse artigo, apresentar as definições de tais conceitos.

O aumento da mais-valia é possível graças a dois processos fundamentais: prolongamento da jornada de trabalho, mais-valia absoluta, e redução do tempo de trabalho necessário, mais-valia relativa. A acumulação do capital é dada por meio da expropriação dos produtores diretos, regida por regras segundo as quais cada capitalista deve destruir o outro (MARX, 1983b).

Com acesso ao crédito e incentivo à inovação, faz-se necessário aumentar o nível de consumo, para que a produção possa ser comercializada ou consumida. Tem-se então o que István Mészáros (2002) chama de sociedade dos descartáveis, na qual há decréscimo na taxa de utilização das mercadorias. Assim, o equilíbrio entre produção e consumo, estritamente necessário para a reprodução do capital, só existirá com o consumo em grande velocidade, ou seja, descartes prematuros.

A inovação interessa ao capitalista para gerar valor de troca. A serviço do capital e subordinada a ele, ela tem dupla funcionalidade: de direcionamento da inovação para a acumulação de capital, conforme mencionado, e de ferramenta de gestão, para que a perda de energia direcionada e aplicada à inovação seja a mínima possível, o que maximiza o resultado esperado, ou seja, a mais-valia.

A inovação contribui tanto para o aumento da mais-valia absoluta, como para a mais-valia relativa. A inúmera quantidade de debates e artigos sobre o balanço entre trabalho e tempo disponível (worklife balance) 
demonstra o ápice da mais-valia absoluta. Além disso, exige-se de cada elemento da corporação uma atitude inovadora diária, sob a ameaça do não-cumprimento dos objetivos financeiros preestabelecidos para determinado período.

A pressão por maior produtividade para o constante aumento de acumulação de capital alimenta a competição acirrada nas organizações, nas quais o "colaborador" (expressão para definir empregados, fornecedores, prestadores de serviços, dentre outros) é desafiado a ultrapassar diariamente seu recorde, sob o pretexto de perder o emprego (ou o cliente, no caso dos fornecedores e terceiros) ou sofrer outras sanções.

A inovatividade - capacidade de introduzir novos produtos e processos - retrata esse cenário (BONELLI et al., 1994). Aliando-se inovação e produtividade, busca-se aumento da mais-valia relativa, para produzir, com menos gastos e tempo, o mesmo tipo de produto ou serviço. Tem-se, então, a inovação como atividade de suma importância para o aumento da mais-valia. Como ferramenta de gestão, ela introduz o controle e a definição do processo da própria inovação. Kaplan e Norton (1997) definem esse processo como investigação das necessidades do cliente, criação de produtos, tudo controlado por indicadores, como percentagem de vendas de novos produtos e tempo para desenvolver outros. Sistemas de recompensa e avaliação por desempenho e competência, balanced scorecard, ações sobre o ambiente de trabalho, dentre outros, são exemplos de métodos para evitar o desperdício de esforços e investimentos nas "linhas" de inovação (ver ALENCAR, 1996).

A literatura do management examinada não aponta o paradoxo entre ambiente com autonomia e favorável a novas idéias e o controle organizacional, realizado pela burocracia, divisão do trabalho, ferramentas de gestão, dentre outros. Além dessa produção bibliográfica, não há autonomia, na acepção da palavra, quando se trata de obter inovação com vistas à acumulação de capital. Há, sim, controle crescente, direcionamento de idéias, esforços, investimentos para alcançar os objetivos financeiros definidos de acordo com o cronograma. Desperdícios são punidos por instrumentos de controle (tais como avaliações de desempenho) nos contínuos vigiar e punir foucaultianos.

Motivação e prazer, base subjetiva para a cooperação e produtividade em altos níveis, também são necessários para a apropriação da criatividade da força de trabalho. Assim, a alienação também conta. 


\section{HÜMANAS}

Os homens, individualizados e sem a noção coletiva, propositadamente desfeita e diluída pela empresa, são conduzidos por um caminho de competição diária com seus pares, induzidos a trabalhar cada vez mais, para que possam sentir prazer do resultado desse esforço. As necessidades dos homens, para as quais ele procura a satisfação, também são produto da autoexpansão capitalista. É a completa subordinação das necessidades humanas à reprodução do valor-de-troca (MÉSZÁROS, 2002).

A inovação acompanha essa expansão do capitalismo e colabora sobremaneira para ela acontecer. Não basta às empresas criar e inovar, sendo a primeira subordinada à última, de maneira controlada, no intuito de aumentar a mais-valia. Também não é suficiente utilizar a inovação como aparelho gestor, conduzindo todos os recursos da corporação para a lucratividade, tampouco apenas aumentar a produtividade por meio da inovação. É preciso aumentar a produtividade da própria inovação, para que o índice de inovação seja o mais alto possível, por meio de medições que incluem o número de lançamentos de novos produtos, vendas, market share, lucratividade, faturamento ou qualquer outro indicador financeiro.

Em tese, a ênfase da inovação nas empresas é uma forma de sobrevivência no mercado, em que ativos e bens intangíveis são mensurados por valores simbólicos, gerados pela criação e aumento das necessidades individuais humanas, e associados muito menos aos valores utilitários do que aos valores de troca. Sendo a inovação e o conhecimento objetos do trabalho concreto, estão sob o direcionamento dos objetivos corporativos de aumento da mais-valia, não podem se expandir sem controle e fora do princípio norteador do capital: o lucro. Sem os controles corporativos, os esforços e investimentos em inovação para gerar mercadorias não seriam maximizados e, conseqüentemente, a mais-valia não atingiria seu ápice.

Afora todos os controles empresariais explícitos, outros implícitos e decorrentes da inter-relação humana nas empresas são fatores determinantes na produção da inovação e em seus resultados. Eles não aparecem como limitantes, mas como alavancas que propiciam a maior produtividade possível das iniciativas de inovação. Aliás, essa é mais uma demonstração de que a inovação, mesmo sendo imaterial e intangível, é parte - e produto - do trabalho concreto, na qual se determina o resultado mensurável para a avaliação de sua contribuição na parcela da mais-valia da corporação. 


\section{Conclusão}

A captura da capacidade criativa do trabalhador é uma necessidade do capital desde sempre, e não invenção recente, como sugere muitas vezes a literatura do management. Marx (1983a) e Schumpeter (1982), dentre outros autores, deixam esse ponto claro. Porém, à medida que o capitalismo avança na produção de serviços e na utilização do trabalho não-repetitivo, criatividade e inovação adquirem crescente importância nas organizações. Na sociedade dos descartáveis (MÉSZÁROS, 2002), o ciclo econômico encolheu, portanto, a taxa de inovação (criatividade transformada em mercadoria) deve ser crescente para sustentar o modelo de acumulação do capital.

As empresas não somente inovaram em processos e métodos para conseguir maior produtividade e competitividade, mas também alteraram o capitalismo empresarial para um novo contexto, no qual o valor simbólico prevalece sobre o valor de troca ou de uso.

O lucro na sociedade do descartável advém cada vez mais da quantidade de acessos a um "produto", cujo custo basicamente existiu durante sua criação e desenvolvimento, mas não no acesso individual. Produtos materiais e uma parcela considerável de serviços apresenta essa lógica de geração da mais-valia, não mais baseada na quantidade de trabalho, mas no monopólio e no preço que os consumidores devem pagar para poder utilizá-los. Essa lógica crescentemente presente em nossa sociedade gera a "indústria do pedágio", na qual se cobram taxas, pois a empresa fabricante detém o que chamamos de monopólio de conhecimento.

Dessa forma, a rapidez da inovação pode perpetuar a mais-valia, gerando características e qualidades exclusivas para o produto ou serviço em questão, mantendo a organização à frente de seus concorrentes. Tal lógica do capitalismo empresarial resulta da combinação de inovação, conhecimento e valor. De acordo com Rifkin (2000), uma drástica conseqüência desse processo de substituição da propriedade pelo acesso é que, quando a cultura é absorvida pela economia, somente os vínculos comerciais restarão para manter a sociedade unida.

O capital imaterial é utilizado como meio para produzir novos consumidores, é a releitura do conceito da destruição criativa. Porém, os novos consumidores serão, invariavelmente, individuais, concebidos na origem como detentores de capacidade de compra, ao contrário do cidadão, em tese, detentor de direitos independentemente da posse de meios de pagamento. 
Assim, o consumidor não contém, per si, necessidades coletivas, desejo de mudança social e preocupação com o bem comum (GORZ, 2005). Em síntese, sobre a base da inovação, três fenômenos se intensificam, com sérias conseqüências para a sociedade: aumento da concentração do mercado (oligopolização), da alienação e do consumo dos produtos descartáveis.

O produto ou serviço inovador permite à empresa praticar preços extorsivos, obtendo o chamado lucro extraordinário (PINDYCK e RUBINFELD, 2004), que realimenta a espiral da concentração, para prejuízo das pessoas, pois, quanto maior for a concentração do mercado, piores serão as condições de acesso das pessoas. Quando tal processo ocorre na produção de medicamentos, por exemplo, tem-se produtos literalmente vitais, cujo preço é inacessível à maioria dos que deles necessitam.

As conseqüências da alienação são sobejamente conhecidas. Inicialmente, conhecia-se a alienação do trabalhador ocupado com tarefas repetitivas e impedido de compreender o resultado completo de seu esforço. Agora se está diante de um trabalhador que é empurrado a acreditar na produção de inovação como exercício de liberdade (por isso, a literatura do management insiste nessa suposta causalidade), não raro em cargos de comando, sendo reenvolvido nos valores do individualismo, quando a vida de todos depende da ética da solidariedade (WOLF, 1990).

A sociedade do descartável, para usar a expressão de Mészáros (2002), dentre muitos outros problemas, é uma das causas dos danos ambientais com os quais convivemos, acrescidos daqueles que mortificarão as próximas gerações. As reflexões apresentadas não pretendem sugerir uma guerra à criatividade e à inovação, mas apontar as conseqüências de ambas, quando operam de acordo com os interesses da acumulação do capital.

\section{Referências bibliográficas}

ALENCAR, E. M. L. S.; FLEITH, D. S. Contribuições teóricas recentes ao estudo da criatividade. Psicologia: teoria e pesquisa, v.19, n.1, p.1-8, 2003.

ALENCAR, E. M. L. S. A gerência da criatividade. São Paulo: Makron Books, 1996.

ALENCAR, E. M. L. S. Criatividade. Brasília: Edunb, 1993.

AYAN, J. $A H A$ ! - 10 maneiras de libertar seu espírito criativo e encontrar grandes idéias. São Paulo: Ed. Negócio, 2001. 
Criatividade, inovação e controle nas organizações

Maria Cristina Sanches Amorim e Ronaldo Frederico

BONELLI, R.; FLEURY, P. F.; FRITSCH, W. Indicadores microeconômicos do desempenho competitivo. Revista de Administração, São Paulo, v.29, n. 2, p.3-19, abr./jun., 1994.

CHESBROUGH, H. W. Open innovation. Boston: Harvard Business School Press, 2003.

CHRISTENSEN, C. M. O crescimento pela inovação. Rio de Janeiro: Campus, 2003.

CLEGG, B.; BIRCH, P. Criatividade: modelos e técnicas para geração de idéias e inovação em mercados altamente competitivos. São Paulo: Makron Books, 2000.

DRUCKER, P. Inovação e espirito empreendedor: prática e princípios. São Paulo: Pioneira Thomson, 2002.

FOUCAULT, M. Microfisica do poder. 21.ed. Rio de Janeiro: Paz e Terra, 2005.

GARDNER, H. A nova ciência da mente. São Paulo: Edusp, 2003.

GARDNER, H. Mentes que criam. Porto Alegre: Artes Médicas, 1996.

GARDNER, H. Estruturas da mente: a teoria das inteligências múltiplas. São Paulo: Artmed, 1994.

GORZ,A. O imaterial: conhecimento, valor e capital. São Paulo: Annablume, 2005.

GRAMSCI, A. Cartas do cárcere. 3.ed. Rio de Janeiro: Civilização Brasileira, 1987.

KANTER, R. M.; KAO, J.; WIERSEMA, F. Inovação: pensamento inovador na 3M, DuPont, GE, Pfizer e Rubbermaid. São Paulo: Negócio, 1998.

KAPLAN, R. S.; NORTON, D. P. A estratégia em ação: balanced scorecard. 5.ed. Rio de Janeiro: Campus, 1997.

KELLEY, T. A arte da inovação: lições de criatividade da IDEO, a maior empresa norte-americana de design. São Paulo: Futura, 2002. 


\section{UMANAS}

KELLEY, T.; LITTMAN, J. As 10 faces da inovação: estratégias para turbinar a criatividade. Rio de Janeiro: Campus, 2007.

KNELLER, G. F. Arte e ciência da criatividade. São Paulo: Ibrasa, 1978.

LAND, G.; JARMAN, B. Ponto de ruptura e transformação. São Paulo: Cultrix, 1992.

MARX, K. O capital: crítica da economia política. v.I. São Paulo: Abril Cultural, 1983a.

MARX, K. O capital: crítica da economia política. v.II. São Paulo: Abril Cultural, 1983b.

MAY, R. A coragem de criar. Rio de Janeiro: Nova Fronteira, 1982.

MÉSZÁROS, I. Para além do capital. São Paulo: Boitempo, 2002.

PAROLIN, S. R. H. A perspectiva dos líderes diante da gestão da criatividade em empresas da região metropolitana de Curitiba-PR. 2001. Dissertação (Mestrado em Administração)-UFRS, Porto Alegre.

PINDYCK, R.; RUBINFELD, D. Microeconomia. 5.ed. São Paulo: Prentice Hall, 2004.

PREDEBON, J. Criatividade hoje. 3.ed. São Paulo: Atlas, 2003.

RAMOS, G. Memórias do cárcere, São Paulo: Martins Fontes, 1980.

RIFKIN, J. A era do acesso. São Paulo: Makron Books, 2000.

ROBINSON, A. G.; STERN, S. Corporate creativity: how innovation and improvement actually happen. San Francisco: Berret-Koehler Publishers, 1997.

SCHUMPETER, J. A. A teoria do desenvolvimento econômico. São Paulo: Abril Cultural, 1982.

SENS, M. J. A criatividade sob a ótica do processo comportamental. 1998. Dissertação (Mestrado em Engenharia da Produção)-Universidade Federal de Santa Catarina, Florianópolis. 
Criatividade, inovação e controle nas organizações Maria Cristina Sanches Amorim e Ronaldo Frederico

TAFFINDER, P. Big change: a route-map for corporate transformation. Londres: John Wiley \& Sons, 1998.

WECHSLER, S. M. Criatividade: descobrindo e encorajando. São Paulo: Ed. Psy, 1998.

WERTHEIMER, M. Productive thinking. New York: Harper \& Row, 1959.

WOLF, P. A miséria do liberalismo. Rio de Janeiro: Paz e Terra, 1990. 